\title{
DENTRE A REFORMA ROCHA VAZ E O ESTADO NOVO: OS PROFESSORES SUPLEMENTARES DO COLÉGIO PEDRO II
}

DOI: http://dx.doi.org/10.1590/2236-3459/74062

\author{
Jefferson da Costa Soares' \\ 'Pontifícia Universidade Católica do Rio de Janeiro (PUC-Rio), Rio de Janeiro/RJ, Brasil \\ Gustavo da Motta Silva" \\ "Pontifícia Universidade Católica do Rio de Janeiro (PUC-Rio), Rio de Janeiro/RJ, Brasil)
}

$\cos 8$

\begin{abstract}
Resumo
O artigo tem como objetivo apresentar resultados de estudo que pretendeu conhecer e compreender aspectos da construção da identidade profissional dos professores do Colégio Pedro II, primeira instituição brasileira de ensino secundário, fundada em 1837. O objeto do artigo são os professores suplementares do Colégio, identificados a partir de análise documental e que atuaram na instituição entre a Reforma Rocha Vaz, de 1925, e o Estado Novo. Os resultados demonstram que o Colégio atinge o número de 219 professores suplementares; que a qualidade do quadro parece não se estender a essa categoria; e que uma minoria dos que passam pelo cargo ascendem às categorias de maior prestígio.

Palavras-chave: professores suplementares, Colégio Pedro II, identidade profissional.
\end{abstract}

\section{ENTRE LA REFORMA ROCHA VAZ Y EL ESTADO NUEVO: LOS PROFESSORES SUPLEMENTARES DEL COLÉGIO PEDRO ॥}

\section{Resumen}

El trabajo tuvo como objetivo presentar los resultados de un estudio cuya propuesta fue conocer y comprender los aspectos de la construcción de la identidad profesional de los maestros del Colégio Pedro II, la primera institución brasileña de enseñanza secundaria, fundada en 1937. El objetivo del artículo es investigar los maestros suplementarios del Colégio, identificados a partir del análisis documental y de la actuación en la institución entre la Reforma Rocha Vaz, en 1925, y el Estado Novo. Los resultados demuestran que el Colégio alcanza la cantidad de 219 maestros suplementarios; que la cantidad del cuadro parece no aumentar en esa categoría; que una pequeña parte de los que pasaron por el cargo llegaron a las categorías de más prestigio. Palabras clave: maestros suplementarios, Colégio Pedro II, identidad profesional.

\section{AMONG THE ROCHA VAZ REFORM AND THE ESTADO NOVO: THE SUPPLEMENTARY TEACHERS OF THE COLÉGIO PEDRO II}

\section{Abstract}

This article aims to present a study which intended to know and understand aspects of the construction of 
professional identity of the teachers from Colégio Pedro II, the first Brazilian institution of secondary education, founded in 1837. The object of this article is the supplementary professors of the Colégio Pedro II, identified from documentary analysis and who acted in the institution between the Rocha Vaz Reform, of 1925, and Estado Novo. The results show that the Colégio Pedro II reaches the number of 219 supplementary teachers; that the quality of the teaching staff of the institution does not seem to extend to this category; that a minority of those who pass through the position ascend to the most prestigious categories.

Keywords: supplementary teachers, Colégio Pedro II, professional teaching Identity.

\section{ENTRE LA RÉFORME ROCHA VAZ ET L'ÉTAT NOUVEAU: LES PROFESSEURS SUPPLÉMENTAIRES DU COLÉGIO PEDRO II}

\section{Résumé}

L'article présent les résultats d'une investigation dont la proposition a été de comprendre les aspects de la construction de l'identité professionnelle des professeurs du Colégio Pedro II. La première institution brésilienne d'enseignement secondaire, fondée en 1837. L'objectif principal de cet article est l'investigation des professeurs supplémentaires de l'institution, identifiés par l'analyse documentaire entre la Réforme Rocha Vaz, en 1925, et l'Estado Novo. Les résultats montrent que le Colégio Pedro II avait 219 professeurs supplémentaires; que la qualité du cadre de professeur n'a pas été la même pour cette catégorie; et une minorité des professeurs supplémentaires a changé de poste jusqu'à une position de prestige.

Mots-clés: professeurs supplémentaires, Colégio Pedro II, identité professionnelle. 


\section{Introdução}

E ste artigo tem origem em investigação que pretendeu conhecer e compreender aspectos da construção da identidade profissional dos professores do Colégio Pedro II, entre 1925 e 1945, período marcado pelas Reformas Rocha Vaz (1925), Francisco Campos (1931 e 1932) e Gustavo Capanema (1942). Buscava-se entender como os professores do Colégio Pedro II, construíram suas trajetórias profissionais, dialogando com referenciais teóricos da história da educação, em especial da história da profissão docente e da sociologia das profissões. Nesse sentido, era fundamental investigar como se configurou o quadro docente do Colégio Pedro II no recorte temporal adotado; quem eram os professores; como se inseriram na instituição; em que categorias se enquadravam; se passavam pelas mesmas etapas ao longo da carreira; de que maneira as mudanças impostas na legislação do ensino secundário impactaram os professores que atuaram no período; como os professores reagiram a elas; e quais modificações acarretaram sobre a organização do quadro docente da primeira instituição de ensino secundário brasileira, criada em 1837, padrão para demais instituições e mantida até os dias atuais pelo Governo Federal.

Partiu-se da tentativa de elaborar pequenas biografias sobre cada professor identificado nas fontes analisadas a saber: Livros de Atas da Congregação do Colégio Pedro II; Regulamentos e os Decretos relativos às reformas educacionais e às mudanças internas do Colégio; Relatórios elaborados pelos diretores do Colégio e encaminhados aos ministros da Educação e Saúde Pública; Manuais didáticos elaborados pelos docentes e adotados pelo Colégio; Anuários; Almanaques de Pessoal Docente e Administrativo, dentre outros. Esses documentos estão disponíveis no Centro de Pesquisa e Documentação de História Contemporânea do Brasil da Fundação Getúlio Vargas (FGV/Cpdoc), no Núcleo de Documentação e Memória do Colégio Pedro II (Nudom) e no Portal da Câmara dos Deputados.

Muitos aspectos sobre a identidade profissional dos professores do Colégio emergiram da documentação investigada e foram analisados com base nos conceitos de Identidade para si e Identidade para o outro, formulados por Dubar (1997), articulados ao de Programa Institucional, de Dubet (2002), até que nos deparamos com a categoria dos Professores Suplementares, deixada de lado pela historiografia monumentalizada sobre 0 Colégio Pedro II. O esquecimento ou a falta de interesse dos pesquisadores por esta categoria se deve, dentre outros motivos, por se tratar da categoria mais baixa hierarquicamente no Colégio no período investigado, pois entre as Reformas Rocha Vaz (1925), Francisco Campos (1931/1932) e Capanema (1942), os Catedráticos ${ }^{1}$ e Docentes Livres $^{2}$ eram os professores mais importantes.

\footnotetext{
1 O Professor Catedrático era profundo conhecedor de sua área de atuação, mas também das demais disciplinas, pois podia ser examinador de qualquer uma delas. A Cátedra era vitalícia e para se tornar catedrático, o candidato devia realizar um exame de cátedra e defender alguma ideia inovadora no campo, além de ter obras científicas publicadas na sua especialidade e ser nomeado pelo Ministro. Segundo o Regimento Interno do Colégio, o Professor Catedrático devia orientar o ensino das matérias que constituíam a sua cadeira; lecionar na totalidade as matérias que constituíam o programa da mesma; tomar parte nas comissões de exames do curso, bem como concursos para docentes; tomar parte nas Congregações; dentre outras.

2 Competia aos Docentes Livres apresentar ao Diretor o programa de seus cursos, antes do início dos mesmos; lecionar em sua totalidade as matérias que constituíam o programa de seus cursos e realizar o respectivo ensino prático; reger cursos das cadeiras para qual tivesse obtido o titulo de docente-livre, por
} 
Nesse artigo identificamos os professores suplementares, suas atribuições, e abordamos as formas de inserção no Colégio e aspectos da construção da identidade profissional dessa categoria no Colégio Pedro II, entre 1925 e 1937.

\section{Os professores suplementares no contexto da Reforma Rocha Vaz}

No contexto da implementação da Reforma Rocha Vaz, Decreto 16.782-A de 1925, e nos anos que se seguiram, o corpo docente do Externato ${ }^{3}$ passava por modificações significativas em razão da criação de turmas suplementares, já que com o aumento do número de matrículas, catedráticos e docentes livres eram insuficientes para lecionar em todas as turmas. Esse quadro se agrava em função de óbitos de professores e da realização dos concursos para preenchimento das vagas por eles deixadas e também pelos que se aposentavam.

Para a regência de turmas suplementares que não pudessem ser confiadas a catedráticos ou a docentes livres, o Diretor tinha a atribuição de designar bacharéis diplomados pelo Colégio ou, na falta destes, "pessoas idôneas" que tivessem o curso completo de humanidades e prática no magistério público ou particular, sendo sempre preferidos os que já haviam servido na regência de turmas nos anos anteriores. (Regimento Interno do Colégio Pedro II, 1927).

Ao analisarmos os relatórios elaborados pelos diretores das duas seções do Colégio na segunda metade dos anos 1920 percebemos mudanças de nomenclatura para fazer referência aos professores que se ocuparam das turmas suplementares, ora chamados de "professores além dos catedráticos", "professores além dos efetivos", "professores estranhos ao quadro docente efetivo", "regentes estranhos", "elementos estranhos" ou "pessoas estranhas", ora chamados simplesmente de "Suplementares".

Com base no "Relatório Concernente aos Anos Letivos de 1925 e 1926, apresentado ao Diretor Geral do Departamento Nacional do Ensino pelo Professor Euclides de Medeiros Guimarães Roxo, Diretor do Externato", verificamos que 66 professores ${ }^{4}$ regeram aulas em turmas suplementares no Externato em 1925 e 115 professores $^{5}$ em

indicação do professor catedrático; tomar assento na Congregação quando estivesse substituindo o professor catedrático ou quando fosse eleito para representar a classe dos docentes livres, não podendo, entretanto, votar na escolha de professor catedrático. Inicialmente, seus títulos de nomeação valiam por dez anos e eram renováveis a juízo da Congregação.

${ }^{3}$ No recorte temporal adotado neste artigo, o Colégio Pedro II era dividido em duas seções, Internato e Externato.

4 São eles: Accacio de Gusmão; Adolpho M. de Los Rios Filho; Alcebiades C. Ferreira; Alcides Fonseca; Alcino José C. Junior; Aldimir de S. Paulo; Alfredo B. da Silveira; Alvaro Teixeira; Annibal Costa; Antonio dos Santos Jacinto Guedes; Antonio F. de Almeida; Aprigio C. de Macedo; Arthur C. Moreira de Araujo; Aryclio P. Chousal; Benevenuto Berna; Danton do Coutto; David Perez; Eduardo C. Albuquerque Sá; Elpidio M. da Trindade; Enoch da R. Lima; Ernani Reis; Francisco V. Filho; George Sumner; Heitor S. de Bustamante; Henrique de Magalhães; Herbert S. de Mendonça; Irineu L. de Freitas; Jacques R. Ferreira da Silva; João de Lamare S. Paulo; João Francisco Lacerda Coutinho; João José Fernandes Veiga; José Bernandino Paranhos da Silva; José Lourenço dos Santos; Julio Cesar de Mello e Souza; Julio Nogueira; Lucas de Moraes e Castro; Manoel Joaquim Guedes; Mario Aleixo; Mario Belleti; Mario Ruch; Mario Vieira de Rezende; Miguel Séve; Mozart Monteiro; Murillo de Araujo; Nelson de Mello e Souza; Octacílio Pessoa; Octavio Lopes de Castro; Odilom Portinho; Oswaldo Gomes; Oswaldo Orico; Oswaldo Serpa; Pandiá T. Castello Branco; Raphael Mayrinck; Raul Bevilacqua; Raul Devesa; Renato Vianna; Ricardo Dias Vieira; Ricardo Ventura Boscoli; Roberto Bandeira Accioli; Roberto da Gama e Silva; Rosalvo Simões; Ruben Descartes Garcia Paula; Sylvio Bevilacqua; Uriel de Azevedo; Véris Jean Alexandre Moitrel; Washington Garcia.

${ }^{5}$ São eles: Abel Pinto; Accacio Buarque de Gusmão; Adolpho Morales de Los Rios Filho; Alberto de Barros; 
1926. Nesse sentido, o número de professores que regeram aulas em turmas suplementares em 1925 quase dobrou em 1926. A partir da comparação entre esses dados, percebemos também, que dos 115 professores que regeram aulas no ano de 1926, 46 lecionaram também no ano de 1925. Não foi possível encontrar, a partir das fontes investigadas, dados mais detalhados sobre a formação, função ou disciplina lecionada por esses professores. Na mesma listagem, encontram-se nomes que revelam grau de parentesco com Professores Catedráticos, como Danton do Coutto e Mario Ruch, parentes de Pedro do Coutto e de Gastão Ruch, respectivos professores catedráticos de História e de Francês.

Os nomes que constam em negrito nas notas de rodapé são de professores que possuem graus de parentesco com catedráticos ou que, em outros tempos, chegaram a esta, que era a categoria mais importante. Consideramos importante a dimensão do grau de parentesco ou das relações familiares, uma vez que no conceito de "identidade" cunhado por Dubar (1997), verificamos que o autor entende que a influência de familiares ou de antigos professores contribui para a escolha profissional. Encontram-se também, professores que se tornaram catedráticos nos anos seguintes, como Alcino José Chavantes Junior, Enoch da Rocha Lima, George Sumner e Roberto Bandeira Accioli, que foram nomeados respectivamente, os dois primeiros, catedráticos de Desenho em 1926, 0 terceiro, catedrático de Física em 1927, e o último, catedrático de História, nomeado em 1943.

A relação de professores que regeram aulas em turmas suplementares no Externato em 1926, além de trazer o nome da primeira mulher a lecionar no Colégio, Maria da Glória Moss, traz os nomes de Nelson Romero e Gildásio Amado, dentre outros que se tornaram catedráticos. O primeiro torna-se catedrático de Latim e/ou Filosofia6 ${ }^{6}$, enquanto o

Alcides Fonseca; Alcino José Chavantes Junior; Alexandre Max Kitzinger; Alfredo Balthazar da Silva; Alfredo Galvão; Aluizio Marques; Alvaro Teixeira; Amado Menna Barreto; Annibal Costa; Antonio Bardy; Antonio dos Santos Jacinto Guedes; Antonio Figueira de Almeida; Antonio Marques Brant Horta; Aprigio de Macedo; Aristoteles Poch; Arthur Cesar Moreira de Araujo; Arthur Walter de Souza; Augusto Feliciano Pereira Pinto; Benedicto Nascimento; Benevenuto Berna; Celso do Prado Kelly; Christiano Augusto Franco; Correggio de Castro; Danton do Coutto; Eduardo Sá; Elpidio Maria da Trindade; Ernani Reis; Ernesto Faria Junior; Ernesto Thibau Junior; Euclydes Godofredo Mendes Vianna; Eugenio Vilhena de Moraes; Fabio Luz; Fenelon Bomilcar; Francisco Salles Malheiros; Gastão Rangel; George Sumner; Gildasio Amado; Heitor Bustamente; Henrique de Magalhães; Henrique Lagden Filho; Henrique Vogeler; Hermann de Brito; Idelfonso Mascarenhas; Irineu Leite de Freitas; Ivans Lins; Jacques Raymundo Ferreira da Silva; João Baptista da Costa Pinto; João Evangelista de Figueiredo Lima; João Francisco Lacerda Coutinho; João José Fernandes Veiga; João Moreira de Araripe Macedo; João Vasconcellos de Albuquerque Mello; Jorge Figueiredo Machado; José Affonso Bandeira de Mello; José Frazão Milanez; José Piragibe; José Rangel; José Silveira Menezes; Julio Cesar de Mello e Souza; Julio Nogueira; Loureiro Sobrinho; Lucas de Moraes Castro; Luiz Claudio de Castilho; Luiz Eugenio de Moraes Costa; Marcio Nery Filho; Marcos Baptista dos Santos; Maria da Gloria Ribeiro Moss (1 ${ }^{\mathrm{a}}$ professora); Mario Barreto; Mario Rezende; Mario Ruch; Mauricio Nogueira; Mecenas Pereira Dourado; Miguel Ramalho Novo; Miguel Séve; Moacyr Malheiros Fernandes da Silva; Murillo de Araujo; Natalicios de Farias; Nelson Romero; Nerval Soares Pereira; Octacílio Pessôa ; Octavio Lopes de Castro; Octavio Simões; Odilon Portinho; Olympio Alves de Carvalho; Oscar Luna Freire do Pillar; Oscar Motta Vianna da Silva; Oswaldo Gomes; Oswaldo Orico; Oswaldo Serpa; Pandiá T. Castello Branco; Paulo Mendes Vianna; Raul Bevilacqua; Raul Devesa; Ricardo Dias Vieira; Ricardo Ventura Boscoli; Roberto Bandeira Accioli; Roberto da Gama e Silva; Roberto Macedo; Roberto Pessoa; Roberto Saidl; Rodolpho Bhering; Rodolpho Paula Lopes Filho; Rosalvo Simões; Ruben Descartes Garcia Paula; Saul de Gusmão; Sylvio Bevilacqua; Sylvio Schleider; Torquato de Mesquita; Tristão da Cunha; Washington Garcia; Zenithilde de Carvalho.

${ }^{6}$ No Anuário de № XV do Colégio Pedro II consta o nome de Nelson Romero, na ordem cronológica, como catedrático de Latim, nomeado em 1935. Na relação por disciplinas, o mesmo nome aparece como catedrático de Filosofia. No livro de atas da Congregação confirmamos que Romero é transferido em 
segundo é nomeado catedrático de Química em 1940 e torna-se Diretor do Externato entre 1947 e 1956.

Com relação aos professores que regeram aulas em turmas suplementares no Internato, não encontramos documentação para o ano de 1925. O "Relatório Concernente aos Anos Letivos de 1926 e 1927, apresentado ao Diretor Geral do Departamento Nacional do Ensino por Pedro do Coutto, Diretor do Internato", permitiu observarmos que, além dos professores do quadro efetivo, serviram em turmas suplementares em 1926, 13 professores $^{7}$. Em 1927, esse número aumentou para 42 professores $^{8}$.

Verificamos, portanto, que o número de professores que regeram aulas em turmas suplementares mais que triplica. Entretanto, apenas 7 dos 42 professores que lecionaram no Internato em 1927, atuaram também no ano de 1926. Não foi possível encontrar, devido à ausência de fontes, informações sobre professores que regeram turmas suplementares no Internato nos anos que se seguiram. Como no caso do Externato, também não foi possível encontrar a partir das fontes investigadas, dados referentes aos anos de 1925 e 1926 mais detalhados sobre a formação, função ou disciplina lecionada por esses professores do Internato. Contudo, foi possível identificar que alguns professores como Danton do Coutto, Abel Pinto, Gildásio Amado, Roberto Accioli e Torquato Mesquita, deram aulas também no Externato em 1927 e em outros anos da segunda metade da década de 1920.

A listagem de professores que regeram aulas em turmas suplementares no Internato em 1926 traz, dentre outros, os nomes Francisco Mozart do Rego Monteiro e Pedro do Coutto Filho, parentes de Clóvis do Rego Monteiro, nomeado catedrático de Português em 1936 e, novamente, de Pedro do Coutto, nomeado catedrático de História em 1925 e que já possuía um parente que deu aulas no Externato em 1925. O próprio Clóvis Monteiro, antes de se tornar catedrático e Diretor do Internato entre 1938 e 1947 e do Externato, entre 1956 e 1961, regeu aulas em turmas suplementares no Externato, em 1928. A relação de 1927, na mesma seção do Colégio, encontramos o nome de Eurico Raja Gabaglia, parente de Fernando Antonio Raja Gabaglia e de Eugênio de Barros Raja Gabaglia, o primeiro era o então catedrático de Geografia e que se tornou Diretor do Externato entre 1933 e 1945, o segundo fora catedrático de Matemática e Cálculo, nomeado em 1890.

Retomamos aqui a situação do Externato, com base no "Relatório Concernente aos

26/09/1938 para a cadeira de Psicologia, Lógica e História da Filosofia. Já no relatório de 1942, elaborado por Fernando Antonio Raja Gabaglia, então Diretor do Externato, o referido professor aparece ocupando a cadeira de Psicologia na Congregação.

7 São eles: Alberto Pequeno; Carlos Porto Carreiro; Douglas Watson; David Peres; Elpídio Maria da Trindade; Fernando Moreira; Francisco Alves dos Reis (Coronel); Francisco Mozart do Rego Monteiro; Gillberto Joyce Paranhos da Silva; Oswaldo Pereira da Silva; Pedro do Coutto Filho; Pedro Paulo Beltrão (Capitão Tenente); Torquato Vieira de Mesquita.

8 São eles: Abel Pinto; Alcides Fonseca; Aldimir São Paulo; Antonio Austregesilo Filho; Ariosto Berna; Carlos Porto Carreiro; Carmem Velasco Portinho; Coryntho da Fonseca; Danton do Coutto; Douglas Watson; Eduardo de Sá; Elpídio Maria da Trindade; Eurico Raja Gabaglia; Fernando Lobo; Fernando Moreira; Francisco Alves dos Reis; Francisco José da Silveira Lobo Jr.; Frederico Mac-Dowell; Genaro d'Avila Mattos; Gilberto Joyce Paranhos da Silva; Gildasio Amado; Guilherme José Jorge; Ildefonso Mascarenhas; João Frederico Lenz Niederauer; João Pinheiro Ribeiro; João Soares Rodrigues; José Lourenço dos Santos; Julio Cesar de Mello e Souza; Livio Barreto Xavier; Luiz de Mello Campos; Nelson Carlos de Mello e Souza; Nestor Victor dos Santos; Othon Pimentel; Pedro do Coutto Filho; Pedro Paulo Beltrão; Raphael Mayrinck; Roberto Accioli; Roberto Macedo; Ruy Alves Campello; Theophanes Brandão; Torquato Vieira de Mesquita; Ubaldino de Moraes Junior. 
Anos Letivos de 1927 a 1929, apresentado ao Diretor Geral do Departamento Nacional do Ensino pelo Professor Euclides de Medeiros Guimarães Roxo, Diretor do Externato". No Externato, no ano de 1927, o número de professores suplementares cai praticamente pela metade em comparação ao ano anterior (1926), passando de 115 para 58 professores ${ }^{9}$, dos quais 19 eram de Português, sendo um deles também de História Universal; 11 de Desenho; 8 de Aritmética; 6 de História Universal; 5 de Geografia, sendo um deles também de História Universal; 3 de Educação Moral e Cívica; 2 de Física; 2 de Química; e 2 de Geometria. A disciplina Português foi, portanto, a que mais careceu de professores no Colégio, seguida da disciplina Desenho. Dos 58 professores suplementares que lecionaram no Externato em 1927, 38 já haviam lecionado em anos anteriores, sendo 17 somente em 1926, 3 somente em 1925 e 18 nos dois anos anteriores. Verificamos, quanto à formação dos professores suplementares que lecionaram no Externato em 1927, que 15 eram bacharéis em Direito, 4 eram engenheiros civis, 4 eram pintores formados pela Escola Nacional de Belas Artes, 2 eram médicos, 2 eram farmacêuticos, 1 era bacharel em letras pelo Colégio Pedro II e, por fim, 1 era químico industrial. Não foi possível identificar a formação acadêmica de outros 29 professores suplementares que atuaram no Externato em 1927.

Identificamos ainda, as funções de origem de 47 professores, sendo que um deles possuía duas funções, fato revelador de que além de lecionarem em turmas suplementares no Colégio Pedro II, esses professores desenvolviam outras atividades na mesma e em outras instituições. Assim, verificamos que 19 eram funcionários, ex-professores ou professores de outras categorias do Colégio Pedro II; 10 eram professores particulares; 9 eram professores ou funcionários de outras instituições; 7 eram docentes da Escola Normal; e 3 eram lentes da Escola Naval. Outros 11 professores suplementares do Externato em 1927 não tiveram suas funções de origem identificadas. O nome de Jurandyr dos Reis Paes Leme, que se torna catedrático de Desenho em 1940 e Diretor do Internato entre 1947 e 1948, aparece na listagem de professores, "considerados estranhos" ao Colégio, que regeram aulas em turmas suplementares do Externato, em 1927. Encontramos também, os nomes de João Ribeiro Filho, que provavelmente possuía grau de parentesco com o catedrático João Ribeiro, de História Geral, nomeado em 1890; e de Octacílio Alvares Pereira, que além de reger aulas de Instrução Moral e Cívica naquele ano, era Secretário do Externato e, alternadamente, da Congregação.

A partir de 1928 começou a vigorar no Colégio o então novo Regimento Interno, que permitia que cada professor catedrático assumisse a regência de quatro turmas

\footnotetext{
9 São eles: Oswaldo Gomes; Ernesto Thibau Junior; João Frederico Lenz Niederauer; Aprigio Carlos de Macedo; Henrique Lagden Filho; David José Perez; Ricardo Ventura Boscoli; José Piragibe; José Lourenço dos Santos; Jacques Raymundo Ferreira da Silva; Raul (?) dos Santos Lima; Torquato de Mesquita; Mario Castello Branco Barreto; Francisco Accioly; Luiz Claudio de Castilho (Comte); Roberto Accioli; Nelson de Mello e Souza; Antonio dos Santos Jacintho Guedes; João José Fernandes Veiga; Antonio Figueira de Almeida; Roberto Freire Seidl; Abel Pinto; Odilon Portinho; Jorge Figueira Machado; Jayme Coelho; Mario Guedes Naylor; Gildasio Amado; Francisco Mozart de Rego Monteiro; Euclides Godofredo Mendes Vianna (Tenente); Milton Pires Barbosa; Octavio Lopes de Castro; Haroldo Bezerra Cavalcanti; Ruy de Lima e Silva; Lino Collet; Danton do Coutto; Miguel Ramalho Novo; João Francisco de Lacerda Coutinho; Mauricio Nogueira; Ricardo Dias Vieira (Comte); Antonio Pereira Caldas; Affonso Parga Nina (Comte); Walter Gomes Cardim; Arlindo Fróes; Ruben Descartes; Pedro do Coutto Filho; José Rangel; Octacílio Alves Pereira; José Paulo Ferreira; Bevenuto Berna; Marcio Nery Filho; Murillo Araujo; Gastão Rangel; Celso do Prado Kelly; Rosalvo Simões; Alvaro Teixeira; Jurandyr dos Reis Paes Leme; João Ribeiro Filho; Roberto da Gama e Silva (Comte).
} 
suplementares, sendo no máximo duas da própria cadeira e as duas restantes de outras disciplinas para as quais tivesse "notória habilitação". Em função do Regimento, foram poucas as turmas regidas por professores suplementares.

Se comparado ao ano de 1927, o número de professores que regeram aulas em turmas suplementares no Externato no ano de 1928, caiu pela metade pelo segundo ano consecutivo, passando de 58 para $29^{10}$. Desses 29 professores suplementares, 7 eram da disciplina Desenho, ou seja, foi a disciplina para a qual havia maior necessidade de contratação de professores; 5 eram de História Universal; 3 de Inglês; 2 de Francês; 2 de Latim; 2 de Geografia; 2 de Química; 2 de Educação Moral e Cívica; 1 de Português; 1 de História do Brasil; 1 de Matemática; e 1 de Física. Identificamos que 7 dos 29 professores suplementares que deram aulas no Externato em 1928 lecionaram nos três anos anteriores (1927, 1926 e 1925), sendo 3 deles professores de Desenho; outros 2 lecionaram nos dois anos anteriores (1927 e 1926); 8 lecionaram apenas no ano anterior (1927); e 2 lecionaram nos anos de 1925 e 1926, ou seja, retornaram à docência em turmas suplementares no Colégio após o intervalo de um ano, o de 1927. Não encontramos registros de que 10 desses 29 professores suplementares tenham lecionado anteriormente em alguma seção do Colégio.

Com relação à formação acadêmica desses 29 professores, identificamos que 5 eram bacharéis em Direito; 3 eram médicos; 2 engenheiros civis; 1 farmacêutico; e 1 pintor diplomado pela Escola Nacional de Belas Artes. Assim, 17 professores não tiveram suas formações identificadas ou já haviam sido identificadas no contexto referente ao ano de 1927. Quanto às funções dos 29 professores que regeram turmas suplementares em 1928, a grande maioria (13) era de docentes livres de disciplinas como Português, História Universal e Desenho, Preparadores de Física e de Química, todos no Colégio Pedro II. Dentre eles, havia ainda o Secretário do Externato e um antigo regente de turmas de Desenho da mesma seção do Colégio. Outros 9 eram professores particulares e 1 era Diretor de outra instituição, o Instituto João Alfredo. Assim, o restante (6) teve suas funções identificadas no contexto do ano anterior ou não foi possível identifica-las. Dos professores que ministraram aulas em turmas suplementares no Externato em 1928, destacamos os nomes de Aimée Ruch, que também possuía grau de parentesco com o catedrático Gastão Ruch, já mencionado anteriormente; e de Luiz Pinheiro Guimarães, que se torna catedrático de Química em 1940.

No ano de 1929, o número de professores que regeram aulas em turmas suplementares cai ainda mais, se compararmos ao ano de 1928. Verificamos que este número passa de 29 para apenas 10 professores $^{11}$. Desses, 4 eram de Desenho; 3 de Português; 2 de Matemática; e 1 de Latim. Nesse sentido, pelo segundo ano consecutivo, a maior demanda foi por professores de Desenho. Podemos inferir também, que apenas 3 professores deram aulas em turmas suplementares do Externato nos cinco anos do período

\footnotetext{
10 São eles: Clovis do Rego Monteiro; Mlle. Aimée Ruch; Octavio Lopes de Castro; Rubem Moitinho; Lenz Niederauer; Paulo Cesar Machado da Silva; Ivan Monteiro de Barros Lins; Roberto Bandeira Accioli; Miguel Séve; Abel Pinto; Mario Guedes Naylor; Mozart Monteiro; Heitor Pereira; Milton Pires Barbosa; Jayme Coelho; Odilon Portilho; J. F. Lacerda Coutinho; Walter Gomes Cardim; Arlindo Fróes; Luiz Pinheiro Guimarães; Octacílio Alves Pereira; José Rangel; Murillo Araujo; José Paulo Ferreira; Raul Bevilacqua; Benevenuto Berna; Jurandyr dos Reis Paes Leme; Alvaro Teixeira; Salvador Carlos de Oliveira.

11 São eles: José Oiticica Filho; Carlos Bezerra de Miranda; Joaquim Mattoso Camara Jr.; Roberto Accioli; Octavio Lopes de Castro; Danton do Coutto; Murilo Araujo; José Paulo Ferreira; Jurandyr dos Reis Paes Leme; Paulo Cesar Machado da Silva.
} 
1925-1929, são eles Roberto Accioli, Octavio Lopes Castro e Murilo Araujo. Danton do Coutto, após lecionar entre 1925 e 1927, retorna em 1929 e outros 2 professores, ambos de Desenho, lecionaram também nos dois anos anteriores (1928 e 1927). Não encontramos registros de que 4 desses 10 professores tenham lecionado anteriormente no Colégio Pedro II. Identificamos, dentre os mesmos que 2 eram bacharéis em Direito, 1 era engenheiro civil e o restante (7) teve sua formação acadêmica mencionada no contexto dos anos anteriores ou não foi possível encontrar informações mais detalhadas. Foi possível ainda, quanto suas funções, identificar que dentre os 10 professores que regeram turmas suplementares em 1929, 4 eram professores particulares, 4 eram Docentes Livres ou Repetidores do Colégio Pedro II e 2 não tiveram suas funções identificadas.

Dentre os professores que ministraram aulas em turmas suplementares, no Externato, em 1929 cabe destacar o nome de José Oiticica Filho, filho do catedrático de Português nomeado em 1925, José Rodrigues Leite e Oiticica.

Embora tenha sido criticada a disposição de 1928, principalmente pelos interessados na obtenção de turmas, Euclides Roxo, então diretor do Externato, acentua que provou "muito bem a aplicação do dispositivo em apreço". Considerava que, de fato, um professor de curso secundário não era, nem devia ser um especialista em determinada disciplina do curso; aliás, mesmo nas escolas superiores, onde a especialização era mais recomendável, era comum encontrarem-se professores que lecionavam duas ou três cadeiras do curso, o que, até certo ponto, era consequência do antigo "regime dos substitutos", que faziam concurso para as cadeiras de uma das antigas seções ${ }^{12}$ (constituídas quase sempre de três cadeiras). Segundo Roxo, era preferível que a regência das turmas suplementares ficasse, sempre que possível, entregue aos professores catedráticos, pelas seguintes razões: tratava-se de uma maneira prática de melhorar os proventos do professor, reconhecidamente mal remunerado; dava-se assim, ao professor, maior interesse pelo próprio cargo, desde que daí viessem todos os meios de subsistência, ao invés de procurar em outras ocupações fora do Colégio, trabalho com que preenchesse o grande número de horas vagas que lhe restavam no correr do dia e com que aumentasse a sua receita mensal; desse maior interesse pelo cargo só podiam resultar vantagens para o ensino, evitando que o professor tivesse, enquanto estava no Colégio, o seu pensamento em ocupações fora do mesmo, muitas vezes alheias ao ensino.

Roxo cita um livro intitulado "Ensino que nos convém", de um Professor chamado Licínio Cardoso para lembrar o que considerava um dos grandes problemas do ensino naquela época, que era "o de prender o professor à escola". No livro, Cardoso preconiza, como medida capaz de solucionar tal problema, permitir que cada professor acumulasse três cadeiras, não só quanto ao trabalho, mas ainda quanto aos vencimentos. Essa medida poderia ser, em parte, realizada no Colégio Pedro II, caso fosse permitida a cada professor a regência de até oito turmas suplementares, quando as houvesse. Com efeito, com as duas turmas efetivas, o professor teria assim dez turmas, o que não era considerado um número excessivo, pois representariam cinco aulas diárias, quando era comum darem, os que lecionavam particularmente, oito ou dez, em diferentes colégios e cursos. Roxo sugeriu o estabelecimento máximo de cinco aulas diárias, sendo três no turno da manhã e duas no

\footnotetext{
12 Neste caso, o termo "seções" não se refere às seções do Colégio, ou seja, Internato e Externato, e sim a áreas disciplinares.
} 
da tarde, ou vice-versa, com intervalo mínimo de uma hora entre os dois turnos ${ }^{13}$.

Outro argumento para que as turmas suplementares ficassem a cargo dos catedráticos quando possível estava fundamentado no fato de que os professores do Colégio estavam mais identificados com os programas e métodos de ensino adotados no mesmo. Além disso, podiam entender-se com os colegas com mais facilidade sobre orientações de como ensinar, do que os "elementos estranhos", entre os quais o corpo docente efetivo encontrava sempre algum antagonismo.

Em virtude do considerável número de alunos matriculados no Externato, foram criadas em 1927, 17 turmas suplementares, sendo cinco no primeiro, sete no segundo, três no terceiro e duas no quarto; em 1928, 14, das quais cinco no primeiro ano, quatro no segundo, três no terceiro e duas no quarto; e, em 1929, igualmente 14 turmas, sendo 4 no primeiro ano, quatro no segundo, três no terceiro, uma no quarto, uma no quinto e uma no sexto ${ }^{14}$.

Observadas as listagens de professores suplementares da segunda metade dos anos 1920, constatamos que tanto a nomeação para docente livre como para professor suplementar, constituíam caminhos para chegar à cátedra. Parece que o cargo de suplementar funcionava como uma primeira etapa na trajetória daquele que almejava esse ideal. Tornar-se docente livre ou assumir interinamente alguma cadeira seriam as etapas seguintes, embora fosse necessário também, o aval do Ministro.

\section{Professores suplementares: entre a Reforma Campos e o Estado Novo}

Para exercício do magistério em institutos oficiais ou sob inspeção, os professores suplementares estavam sujeitos ao prévio registro na Diretoria Nacional de Educação, em que se converteu o Departamento Nacional de Ensino:

Fica mantido, no Departamento Nacional de Ensino, o Registro de Professores, destinado à inscrição dos candidatos ao exercício do magistério em estabelecimentos de ensino secundário federais, equiparados, livres ou sob inspeção preliminar. (Art. 87, dec. №. 21.241, de 04/04/1932).

As exigências para a consumação desse registro eram representadas por uma documentação muito precária, quase que ao alcance de quem jamais lidou com causas do ensino e assim inexplicavelmente mantida até aquele momento. Era pouco o exigido, quase nada. Vejamos agora como o Colégio Pedro II fazia cumprir essa exigência, ao admitir elementos para o magistério suplementar. Para maior facilidade de leitura, consideramos preferível a organização dos Quadros que se seguem, deixando para o final os comentários que se impõem. Houve a necessidade de repetir nomes nos inclusos Quadros porque existiam professores suplementares que lecionavam em diversas disciplinas, podendo-se, então, dar-se o caso de registro em umas e em outras não. Os dados foram adquiridos a partir das informações fornecidas pelo Consultor Jurandir Lodi ${ }^{15}$ ao Ministro.

13 GUIMARÃES ROXO, Euclides de Medeiros. Relatório concernente aos anos letivos de 1927 a 1929. Apresentado ao Exmo. Sr. Diretor Geral do Departamento Nacional do Ensino pelo Professor Euclides de Medeiros Guimarães Roxo, Diretor do Externato. Rio de Janeiro: Colégio Pedro II, 1930.

14 Idem.

${ }^{15}$ FGV, CPDOC. Jurandir Lodi. O Colégio Pedro II, [1940]: GC g 1935.10.18/1, r. 36. 
Dos 35 professores suplementares que lecionavam Português ${ }^{16}$ naquele momento, 13 estavam registrados nessa disciplina na Diretoria Nacional de Educação e 22 deixaram de cumprir essa exigência da lei.

Verificamos ainda, segundo o documento investigado, que desses professores, 5 eram mulheres, uma delas já idosa e considerada "cumpridora dos seus deveres"; 8 eram elementos antigos no magistério ou com atuação no magistério público municipal, um deles "faltava muito" e estava registrado em outra disciplina. Outros 13 eram considerados "novos no magistério", considerados inexperientes ou havia algum tipo de restrição quanto ao nome. Um deles, inclusive, aparentava ser menor de idade, conforme a fonte investigada. Destes, considerados "elementos novos", encontramos mais 2 nomes que estavam registrados em outras disciplinas. $O$ documento refere-se ainda, a 8 nomes considerados "bons elementos", um deles também encontrava-se registrado em outras disciplinas. Havia também 1 professor dirigente do ensino de Alemão, que para além da carreira no magistério, era deputado estadual no Estado de Minas Gerais. Não encontramos observações sobre 3 professores.

Referentes à disciplina Francês havia 39 professores suplementares ${ }^{17}$ que a lecionavam pelo método direto, dos quais 15 estavam registrados na referida disciplina e 22 não se registraram. Havia, inclusive, dúvidas se o próprio dirigente do ensino contratado pelo Ministro possuía registro. Francês é a disciplina na qual se encontrava o maior número de professoras suplementares, totalizando 21, mesmo número referente àqueles considerados "bons elementos" pelo autor do documento investigado. Encontra-se na mesma relação o nome de uma professora, sobre a qual havia dúvidas quanto ao registro, 1 professor italiano, quase cego, que possuía uma má pronúncia e já havia sido dispensado de uma outra instituição e, por fim, o nome de um professor que recebia muitas queixas dos alunos referentes às aulas dadas. Não encontramos informações mais precisas sobre 15 dos 39 professores suplementares de Francês.

Com relação aos 32 professores suplementares de Inglês ${ }^{18}$, que lecionavam pelo

16 São eles: Arthur Torres; Aurea de Salles Pereira Leite; Celso Cunha; Clara Oiticica; Domingos Ormond; David José Perez; Ernani Reis; Francisco Augusto de La Rocque; Gilberto Chockatt de Sá; João Baptista Ferreira Pereira; José Junqueira Ferreira da Silva; José Alencar Arraes; Luiz Carlos de Oliveira; Mario Martins; Newton da Silva Maia; Otilia Reis; Pedro do Coutto Filho; Petronio Motta; Pedro Calheiros Bomfim; Roberto Pompeu Souza Brasil; Renato Firmino Mais Mendonça; Tristão da Cunha; Torquato Vieira de Mesquita; Anna da Gloria Santos de Araujo; Almir Carneiro Mattos Peixoto; Alcides Carlos d`Arcanchy; Calil Cassab; Edmundo Silva; Francisco Salles Malheiros; Haroldo C. de Oliveira; José Maria Leoni; José Lourenço dos Santos; Maria de Lourdes Nogueira; Sylvio Edmundo Silva; Vicente de Paula Reis.

17 São eles: Antonio Carneiro Leão; Alvares de Azevedo Macedo; Maria Las Casas A. e Souza; Nair Quintella; Aimée Ruch; Alice Santour; Alexandre Brigole; Amalia Caminha Machado; Amalia Honold; Claro Calmon; Eva Manuel; Felicidade Petit Lopes; Gilda de Carvalho; Henrique Lagden; João Frederico Lenz Liederauer; Joaquim Maximo de Carvalho Junior; Laura Sampaio Vianna; Maria de Lourdes Sá Pereira; Madaleine Manuel; Maria Velloso; Maria Souza da Motta Ferreira; Maurício José Nerval de Gouveia; Mary Lucy Torres Martins; Nadir Raja Gabaglia; Patrick de Forrey; Raul Penido Filho; Sylvia Falleti; Alfredi Galvão; Miguel Arthur Chiarappe; Salomão Capper; Clara de Paiva Galvão; Elemir Queiroz; Edgar Liger Belair; Francisca de Almeida Aguiar; José Alencar Arraes; Hermano Londan; Jayme Porto Carrero; Lucia Uchôa Cavalcanti; Maria Chermont Costa.

18 São eles: Oswaldo Serpa; Alda Drummond; Candelaria Lima Mendes; Clemente Capper; Christiano Franco; Carlos Ramos; Diva Alves Pinto; Daniel do Carmo; Douglas Watson; Guimar Saraiva; José Silvano Bueno; José Domingos Santos Junior; José Fernando; Maria Pinheiro Guimarães; Melissa Hull; Mary Mandin; Manuel Fialho da Motta; Maria dos Reis Campos; Paulo Cesar Machado Silva; Paulo Sarmento Soares; Richard J. Euke; Sebastião Angelico de Souza; Sidronia C. Guimarães; Vicente de Miranda Reis; Walter Luiz Balmann; Eridéa de Barros; Hermano Londan; Heinch von Wieser; Oswaldo Carlos Ferrão; Altamiro de Castro; Eduardo Leite; Vicente Paulo Siffert Silva. 
método direto, 14 eram registrados na forma da lei e 17 deixaram de cumprir essa exigência. Havia dúvidas acerca do professor dirigente, contratado pelo Ministro. Essa disciplina também contava com algumas professoras, totalizando 11. Dos 32 nomes, 8 eram considerados "bons elementos" e em outros 23 casos, não foi possível encontrar observações mais detalhadas sobre suas trajetórias.

No que diz respeito à disciplina Latim, dos 5 professores suplementares ${ }^{19}$, apenas 2 se encontravam registrados. Desses 5 nomes, 4 eram considerados "bons elementos" e 1, que era Padre, sofria reclamações dos alunos, que alegavam incompetência e utilizaram veículos da imprensa para manifestar tais críticas.

Lecionavam Matemática 20 professores suplementares ${ }^{20}$. Desses, 7 cumpriram as exigências da lei, registrando-se. Outros 11 não estavam registrados e de 2 não foram colhidos dados que permitissem afirmativa. Eram considerados "bons elementos" 8 professores, 1 deles era também Preparador da cadeira de Cosmografia. Em 3 casos foram observadas "más informações", que não foram descritas, mas num desses casos há o nome de um professor considerado "competente" pelo autor do relatório investigado. Não foi possível fazer observações mais detalhadas sobre 9 dos 32 professores suplementares da Matemática.

Dos 19 professores que lecionavam turmas suplementares de Geografia ${ }^{21}, 6$ se encontravam registrados e 13 não. Dentre esses nomes, constatamos a presença de 2 professoras. Foram considerados "bons elementos" 4 nomes, um deles era Preparador da cadeira e irmão de Fernando Antonio Raja Gabaglia, então Diretor do Externato do Colégio Pedro Il e catedrático da referida disciplina. Nadir Raja Gabaglia, nome presente na lista de Francês e que também possuía grau de parentesco com os nomes supracitados, também está presente na lista de Geografia. Outros 3 nomes eram recém-egressos do próprio Colégio, alunos de Geografia da Universidade do Distrito Federal, cadeira que funcionava no Colégio, entretanto, foi considerado "inexperiente" apenas 1 desses nomes. Havia ainda, 1 professor que também seguia carreira militar e 1 professor considerado "antigo elemento". Em 10 casos não foi possível encontrar maiores informações sobre o perfil profissional.

Com relação aos 11 professores suplementares de Desenho ${ }^{22}$, somente dois se encontravam registrados. Havia outras turmas de Desenho que foram confiadas a docentes livres. Apenas 1 era considerado "bom elemento" e outro "faltava muito". Sobre os outros 9 nomes não foi possível encontrar informações mais detalhadas.

Não foram colhidos dados que conduzissem a afirmativas quanto ao registro, no

\footnotetext{
19 São eles: Jorge Delaura Meyer; Roberto Bandeira Accioli; Agenor Francisco de Macedo; José de Aquino (padre); Oscar Cunha.

20 São eles: Adalberto Cumplido de Sant'Anna; Antonio Moreira; Danton do Coutto; Gaspar S. M. Rodrigues Pereira; Henrique Saule; Haroldo Cecil Pollard; Irineu de Freitas; João de Lamare S. Paulo; Julio Cesar de Mello Souza; Mario de Castro Cunha; Octavio Castro; Paulo Franklin Ribeiro Mendes Vianna; José Carlos de Mello e Souza; Amado Menna Barreto; Ernesto de Arruda Mello; José Joaquim Cosme Pinto; Luiz Vieira de Castro; Mario Marcondes Calazans; Murillo Braga; Victor Carlos da Silva.

21 São eles: Anna O. Porto Carrero; Carlos Domingues; David Penna Aarão Reis; Fernando Segismundo Esteves; Hugo Segadas Vianna; Heraldo Filgueiras; João Raja Gabaglia; José Candido Sampaio Lacerda; Joaquim Murillo Silveira; José Bartholo Silva; Miguel Angelo Dantas Seve; Nadir Raja Gabaglia; Oscar Tenono; Odilon Motta Athayde Fortinho; Emmanuel Chrispiniano Reis Martins; Eurico Figueiredo Costa; Francisco de Souza Brasil; Joel Quaresma de Moreira; Pedro Pereira da Cunha.

22 São eles: Elysio Dantas; José Saboia Barbosa; João Ribeiro Filho; Orlando Alvarenga Gaudio; Rubens Porto; Umbelino Pereira Martins; Aldary Toledo; Amelio Dias de Mottaes; Claudionor Teixeira Braga; Moacyr Paranhos Barbosa; Walfrido Freire.
} 
que diz respeito aos 8 professores suplementares de Química ${ }^{23}$. Sabemos apenas que havia 1 professora, que teria sido a primeira mulher a lecionar no Colégio; 2 professores que ocupavam a cátedra interinamente, sendo um deles o Professor Gildásio Amado, que se torna catedrático da referida disciplina em 1940 e em 1947 é designado para a diretoria do Internato do Colégio Pedro II, assumindo em 27 de fevereiro do mesmo ano e permanecendo no cargo até 1956; 1 professor considerado "bom elemento" que também era Preparador da cadeira; e outro que havia sido considerado inabilitado em dois concursos a que se submeteu. Encontramos também, nos documentos consultados no Cpdoc/FGV, indícios das dificuldades que os professores do curso complementar ${ }^{24}$, principalmente os de Química enfrentavam:

Só a inconsciência poderá afirmar que o laboratório de Química, por exemplo, satisfaz a exigência da lei (“... estudo intensivo, com exercícios e trabalhos práticos individuais...") ou do ensino. E o Colégio Pedro II não dá trabalhos práticos, como devia dar, porque não pode dar: não tem com que. E é de lamentar, porque o corpo docente do complementar, se quiser trabalhar, é bom. (LODI, Jurandir. [O Colégio Pedro II]. Rio de Janeiro: FGV/CPDOC, [1940]. GC g 1935.10.18/1, r. 36).

Após essa observação, o autor dos documentos (Jurandir Lodi) enumera uma relação de 31 professores do curso complementar, afirmando que "de parte de ligeiras exceções, o corpo docente é ótimo". Entretanto, o delator questiona o que adiantaria ter um corpo docente assim considerado, se, por outro lado, era constituído quase todo de professores sobrecarregados de outras aulas, que não podiam se dedicar à parte prática. A questão dos trabalhos em laboratórios era considerada preocupante, diante da sua importância, do seu "enorme" alcance didático.

No que diz respeito aos professores de Ciências Físicas e Naturais, 16 suplementares $^{25}$ lecionavam turmas extranumerárias. Desses, somente 5 estavam registrados nessa disciplina. Pelo seu grande significado na vida estudantil, esta era considerada uma das mais importantes cadeiras do currículo naquela época, entretanto, era a que mais sofria com a falta de estrutura: não possuía sala própria, não tinha laboratórios, nada. "Era doloroso", segundo Jurandir Lodi, redator do documento. Dentre os suplementares desta disciplina, atuavam 2 professoras. Embora contasse com 1 professor que ainda estava na condição de "aprendiz" e outro na condição de "estudante", é para outros 2 nomes que se destina a qualificação de "inexperientes", um deles era considerado "quase uma criança" e substituía a irmã, que era casada com um militar e encontrava-se no Estado do Mato Grosso. Sobre o outro, havia "más informações", parece que se tratava de um professor que se prendia ao livro didático e a leitura continuada era recorrente em suas aulas. Havia ainda, 1 professor aposentado, 1 "elemento antigo" e um militar, enquanto para

\footnotetext{
${ }^{23}$ São eles: Arlindo Froes; Alcides Jardim; Argemiro Pinto; Gildásio Amado; Pinheiro Guimarães; Maria da Glória Moss; Vinicius Ferreira Chaves; Jorge Kubrusly.

${ }^{24}$ A Reforma Francisco Campos estabeleceu que o ensino secundário, oficialmente reconhecido, devia ser ministrado no Colégio Pedro II e em estabelecimentos sob regime de inspeção oficial. O ensino secundário passou a compreender dois cursos seriados: o Fundamental, que oferecia a formação básica e o Complementar, obrigatório para os candidatos à matrícula em determinados institutos de ensino superior e feito em 2 anos de estudo intensivo.

25 São eles: Ary Menezes; Cleto Seabra Velloso; Francisco Valles de Freitas Lima; José Gerardo de Lamare S. Paulo; José Oiticica Filho; José Rangel; Maria Luiza de Villamor Amaral; Nilda Bethlem Arrêas; Newton Bethlem; Waldir Sergio Ferreira; Affonso Aranha Parga Nina; Frederico Castro Menezes; Miguel de Azevedo; Maciel Pinheiro; Odilon Rocha e Souza; Renato Franco.
} 
outros 6 nomes não foram encontradas observações ou detalhes sobre suas trajetórias ou perfil profissional.

Somente 2, dos 6 professores suplementares de História Natural ${ }^{26}$ não estavam registrados. Os dois Peryassú eram médicos. Antonio, o pai, era do Instituto Oswaldo Cruz. Consta ainda, sobre um dos irmãos, a informação de que era da região de Manguinhos. $A$ relação de suplementares contava ainda com o Preparador da cadeira, 2 nomes considerados "bons elementos", um deles também classificado como "antigo" e mais 2 nomes qualificados como "elementos novos".

Dos 19 professores suplementares de História da Civilização ${ }^{27}, 7$ se encontravam registrados. Havia dúvidas quanto a um. Outros 11 não estavam registrados na disciplina que lecionavam. Havia incertezas sobre um nome, no que diz respeito ao registro. Encontramos 2 professoras na listagem suplementar da disciplina. Podemos destacar que 3 professores eram alunos da antiga Universidade da Prefeitura e eram considerados "novos", enquanto outros 5 eram considerados "antigos", dentre eles 1 também classificado como "bom elemento" pelo autor do relatório. Constatamos ainda, dentre os professores da disciplina, e existência de 2 estudantes e 1 nome considerado "elemento novo". Para 8 nomes não foi possível encontrar informações.

Havia ainda, 8 professores suplementares de Física ${ }^{28}$, dos quais 1 estava com o processo de registro em curso, 2 estavam registrados na disciplina e 5 a lecionavam independentes da formalidade legal. Constatamos que 3 nomes se enquadravam também na categoria de Preparadores, sendo 1 da cadeira, também classificado como "ótimo elemento", 1 de Cosmografia e um terceiro, cuja especificação não foi detalhada na fonte investigada. Constam também os nomes de 1 militar e de um estudante de medicina na relação de suplementares de Física, enquanto não encontramos aspectos identitários mais detalhados de outros 3 nomes, embora um deles tivesse o sobrenome "Dodsworth", que pode indicar grau de parentesco com o substituto em 1924, que se torna catedrático de Física em 1925, ex-diretor do Externato e político, Henrique de Toledo Dodsworth Filho e que, segundo Barros (2009, p. 192), era amigo de Vargas no contexto das comemorações do centenário do Colégio, em 1937.

O $219^{\circ}$ professor era João de Lamare São Paulo, único professor de Cosmografia lecionava turma extranumerária. Era oficial da Armada, Preparador da cadeira e não estava registrado na disciplina. Era também professor suplementar de Física e em observações anteriores, considerado "bom elemento". João de Lamare São Paulo provavelmente tinha grau de parentesco com José Gerardo de Lamare São Paulo, professor suplementar de Ciências Físicas e Naturais, criticado por dar aulas com o livro aberto e considerado inexperiente.

Causou estranhamento o fato de não termos encontrado nas listagens de

\footnotetext{
${ }^{26}$ São eles: Antonio Peryassú; Demetrio Peryassú; Ernesto Paiva Marreca; João Carlos Restier Backheuser; Adhemar Aderbal da Costa; José Curvello de Mendonça.

${ }^{27}$ São eles: Eremildo Vianna; Fernando Segismundo Esteves; Guy José Paulo de Hollanda; Heitor Pereira; Julio Esnaty; Marcos Baptista dos Santos; Odilon Portinho; Pedro do Coutto Filho; Roberto Bandeira Accioli; Roberto Freire Seidl; Wanda de Mattos Cardoso; Sidney Suzanno de França Miranda; Zuleide Cesar Burlamaqui; Alfredo d'Escragnolle Taunay; Clemenceau de Azevedo Marques; Dunshe de Abranches; Ernesto Silva; Geraldo Sampaio de Souza; Octavio Canejo.

28 São eles: João de Lamare S. Paulo; Walter Cardim; Affonso Aranha Parga Nina; Edmundo Brabosa Vianna; Henrique Feio Galvão; Luiz de Castro Dodsworth Martins; Mario de Souza; Theodomiro Rothier Duarte.
} 
professores suplementares produzidas para verificação daqueles que possuíam o "Registro de Professores", nomes de professores suplementares de Sociologia. Esse fato pode ser indicador de que o então Professor Catedrático, Delgado de Carvalho, tenha sido o único professor a ministrar as aulas de Sociologia do curso complementar nos anos 1930. Entretanto, essa hipótese merece ser mais bem investigada, uma vez que nesse período a Sociologia ganha força ao figurar nos cursos complementares do ensino secundário com maior carga horária e o Colégio Pedro II aumenta progressivamente o número de matrículas, o que leva à necessidade de ampliação do seu quadro docente. Entre 1925 e 1937, o número de matrículas passa de 1343 para $2900^{29}$.

No que se refere às outras disciplinas, tal fato levou à contratação de professores suplementares, consequentemente a possibilidade dos alunos terem oportunidade de ter aulas com os catedráticos diminuía consideravelmente. Jurandir Lodi alertou em seu relatório para a possibilidade de, dentre os professores suplementares listados, existirem elementos que estivessem aquém dos próprios alunos em termos de conhecimento.

Entre os professores listados, conforme observado, não foram computados os professores catedráticos e docentes livres, mesmo quando lecionavam turmas suplementares de outras disciplinas. Foi possível constatar assim, com relação aos professores suplementares do Colégio Pedro II, que totalizavam $219^{30}$, mais da metade não possuía o registro naquela época, ou seja, 127 professores. Outros 77 se encontravam registrados, enquanto o relator da fonte analisada não soube informar a situação de 15 professores com relação ao registro. Catedráticos e docentes livres, que totalizavam 50 eram isentos por lei, de se registrarem. No mesmo documento, é reforçada a competência dos professores catedráticos:

Corpo Docente de primeiríssima água, escol brilhantíssimo, não há cátedra do Colégio Pedro II ocupada por quem não seja, incontestavelmente um mestre, na legítima acepção do termo. Plêiade luminosa, para honra da cultura nacional. (LODI, Jurandir. [O Colégio Pedro II]. Rio de Janeiro: FGV/CPDOC, [1940]. GC g 1935.10.18/1, r. 36).

Observamos também, uma grande quantidade de professores, considerada "inexplicável" pelo autor do documento encontrado, mas indispensável para ocupar a atenção dos milhares de alunos matriculados no Colégio Pedro II naquela época. Tratavase de uma situação que apresentava diversos aspectos considerados "muito graves" por Jurandir Lodi, para os quais era indispensável a atenção da administração, principalmente pelo fato de os professores suplementares serem selecionados por indicação dos diretores do Colégio.

Durante o período investigado e no que diz respeito aos "Professores Suplementares", vigorou a prerrogativa dos contratos temporários em consequência do aumento do número de alunos matriculados. Embora essa forma de contratação tenha se constituído para alguns professores como uma via de acesso às categorias mais elevadas, verificou-se a existência de um quadro que não contribuiu de maneira positiva para a

\footnotetext{
29 Fonte: Laet, 1925; Guimarães Roxo, 1928; Coutto, 1928; Pereira, 1937; CPDOC/FGV - Arquivo Gustavo Capanema G C 35. 10.18/1, pasta V -11, série g.

${ }^{30}$ Massunaga (1989) e Dias (2008) contabilizaram 218 professores suplementares. Tal diferença se deve ao fato de que enquanto as autoras contabilizaram 4 professores de Latim, verificamos a existência de 5 nomes, conforme Quadro 05.
} 
construção de uma identidade sólida. Por mais que os contratos fossem renovados, seja por nomeação ou por concurso, o fato dos "Suplementares" não pertencerem ao quadro efetivo e de não contarem com garantias trabalhistas, pode ter gerado instabilidade, insegurança e não comprometimento, conforme assevera Dubar (1997).

\section{Conclusão}

A qualidade do corpo docente efetivo no período investigado, tão exaltado na historiografia sobre o Colégio Pedro II, parece não se estender da mesma forma aos professores suplementares que atuaram no mesmo período. Quando analisamos os dados referentes a essa categoria, verificamos que o espaço destinado às "observações" estava em branco para 87 dos 219 professores que compunham o quadro docente suplementar do Colégio em 1937, o que pode ser um indício de que o próprio Consultor do Governo encontrou dificuldades para levantar informações sobre o perfil desses professores. Se por um lado encontramos para 56 nomes a observação "bom elemento", por outro, encontramos observações que revelam inexperiência, alto número de faltas e queixas de alunos para com alguns professores. Não podemos perder de vista o quão contingente é esse conceito de "bom elemento", já que depende daquilo que se considerava aceitável e desejável.

Em termos gerais, o corpo docente do Colégio Pedro II era constituído, no período estudado, por um número maior de elementos do sexo masculino, face aos elementos do sexo feminino. Não constatamos a presença de professoras nas reuniões da Congregação ou ocupando a Direção de alguma das seções do Colégio nesse período. As professoras ocuparam os cargos de professoras suplementares, principalmente nas disciplinas de línguas vivas.

Se por um lado a Congregação do Colégio era um lugar de conflitos e de disputas, percebemos que se trata também de um espaço de convivência, de partilha de saberes e, principalmente, de resistência. Embora fosse possível perceber neste espaço a existência de um tipo de solidariedade ou de corporativismo, parece que tudo estava à margem dos professores suplementares, provavelmente pelas dificuldades na construção de uma identidade sólida ou pela ausência de um espaço que proporcionasse uma relação de maior proximidade entre os professores suplementares, os professores das categorias mais elevadas hierarquicamente e o Colégio.

O aumento sempre crescente do número de alunos matriculados no Externato tornou impossível o ensino somente pelos membros da Congregação. Foi necessária a admissão de professores suplementares, cuja escolha, a princípio, era feita pelo Diretor e submetida à aprovação da Congregação. Mais tarde, a designação daqueles professores passou a ser da competência exclusiva do Diretor. Em face do decreto 1.555 de 7 de abril de 1937, o Governo determinou que a admissão dos professores suplementares fosse feita mediante concurso de títulos e documentos, expedindo o Ministério da Educação". Os professores assim contratados, pela primeira vez, em 1937, ficaram obrigados a dar pelo menos 12 horas de aulas semanais.

Mesmo que para uma minoria, se tornar professor suplementar do Colégio era um caminho para os que almejavam chegar às categorias mais elevadas hierarquicamente, docente livre e catedrático, respectivamente. Mostramos que muitos professores suplementares faziam parte de clãs familiares no interior do Colégio. 
O recorte temporal adotado no artigo é considerado por Nagle (1974) e Silva (1969) como um período de consolidação da institucionalização do ensino secundário no Brasil. Entendemos, portanto, que por atuarem nesse período, os professores suplementares, que assumiram grande parte das aulas, contratados em condições precárias e que ocupavam o lugar mais baixo na hierarquia profissional docente do Colégio, também contribuíram para esse processo. Nesse sentido, investigar os esforços por eles empreendidos pode se configurar em contribuição relevante para a História da Educação, em especial, para a História da Profissão Docente.

\section{Referências}

ALVES, Rosana Llopis. Trajetórias femininas no Colégio Pedro II. In: ANPUH, 2 / SIMPÓSIO NACIONAL DE HISTÓRIA, - XXV, 2009. Fortaleza/CE. Anais... Fortaleza: ANPUH, 2009. p. 1-10.

BARROS, Orlando de. O Colégio Pedro II no Estado Novo. In: CHAVES, Miriam Waidenfeld; LOPES, Sonia de Castro (Orgs.). Instituições educacionais da cidade do Rio de Janeiro: um século de história (1850-1950). Rio de Janeiro: Mauad X, Faperj, 2009. p. $189-216$.

BRASIL. Decreto $n^{\circ} 16.792$ - A de 13 de janeiro de 1925. Reforma Rocha Vaz. Coleção de Leis do Império e da República. Disponível em: <http://www2.camara.gov.br>. Acesso em: 30 jul. 2011.

Decreto no 19.890 de 11 de abril de 1931. Reforma Francisco Campos. Coleção de Leis do Império e da República. Disponível em: <http://www2.camara.gov.br>.

Decreto $n^{\circ}$ 21.241, de 04/04/1932. Dispositivos de confirmação da Reforma Francisco Campos. Coleção de Leis do Império e da República. Disponível em: $<$ http://www2.camara.gov.br>.

COLÉGIO PEDRO II. Anuário do Colégio Pedro II: 1926-1927. Rio de Janeiro, 1928. v. VII. Núcleo de Documentação e Memória do Colégio Pedro II (Nudom/CPII).

Anuário do Colégio Pedro II: 1928-1934. Rio de Janeiro, 1937. v. VIII. Núcleo de Documentação e Memória do Colégio Pedro II (Nudom/CPII).

Anuário do Colégio Pedro II: 1935-1936. Rio de Janeiro, 1939. v. IX. Núcleo de Documentação e Memória do Colégio Pedro II (Nudom/CPII).

Anuário do Colégio Pedro II: 1937-1938. Rio de Janeiro, 1944. v. X. Núcleo de Documentação e Memória do Colégio Pedro II (Nudom/CPII).

Anuário do Colégio Pedro II: 1939-1941. Rio de Janeiro, 1943. v. X. Núcleo de Documentação e Memória do Colégio Pedro II (Nudom/CPII).

Anuário do Colégio Pedro II: 1949-1950. Rio de Janeiro: Ministério da Educação e da Cultura, 1954. v. XV. Núcleo de Documentação e Memória do Colégio Pedro II (Nudom/CPII).

Livro de Atas da Congregação do Colégio Pedro II: 1925-1934. Rio de Janeiro, 1925-1934. Núcleo de Documentação e Memória do Colégio Pedro II (Nudom/CPII).

Livro de Atas da Congregação do Colégio Pedro II: 1934-1946. Rio de Janeiro, 1934-1946. Núcleo de Documentação e Memória do Colégio Pedro II (Nudom/CPII).

Regimento Interno. Rio de Janeiro, 1927. Núcleo de Documentação e Memória do Colégio Pedro II (Nudom/CPII). 
COUTTO, Pedro. Relatório concernente aos anos letivos de 1926 e 1927. Apresentado ao Exmo. Sr. Diretor Geral do Departamento Nacional do Ensino por Pedro do Coutto, Diretor do Internato. Rio de Janeiro: Colégio Pedro II - Internato, 1928.

DALLABRIDA, Norberto. A Reforma Francisco Campos e a modernização nacionalizada do ensino secundário. Educação, v. 32, n. 2, p. 185-191, maio/ago. 2009.

DIAS, Amália. Apostolado cívico e trabalhadores do ensino: História do Magistério do ensino Secundário no Brasil (1931-1946). 2008. 242 f. Dissertação (Mestrado em Educação) - Universidade Federal Fluminense, Rio de Janeiro, 2008.

DORIA, Escragnolle. Memória histórica do Colégio Pedro II. Brasília: Instituto Nacional de Estudos e Pesquisas Educacionais, 1997. Edição original: 1937.

DUBAR, Claude. A socialização: construção das identidades sociais e profissionais. Porto: Porto Ed., 1997.

DUBET, F. Le declin de l'institution. Paris: Éditions du Seuil, 2002.

Mutações cruzadas: a cidadania e a escola. Revista Brasileira de Educação, Rio de Janeiro, v. 16, n. 47, p. 289-305, maio/ago. 2011.

GUIMARÃES ROXO, Euclides de Medeiros. Relatório concernente aos anos letivos de 1925 e 1926. Apresentado ao Exmo. Sr. Diretor Geral do departamento Nacional do Ensino pelo Professor Euclides de Medeiros Guimarães Roxo, Diretor do Externato. Rio de Janeiro: Colégio Pedro II, 1928.

Relatório concernente aos anos letivos de 1927 a 1929. Apresentado ao Exmo. Sr. Diretor Geral do Departamento Nacional do Ensino pelo Professor Euclides de Medeiros Guimarães Roxo, Diretor do Externato. Rio de Janeiro: Colégio Pedro II, 1930.

LAWN, Martin. Os professores e a fabricação de identidades. Currículo sem fronteiras, v. 1, n. 2, p. 117-130, jul./dez. 2001.

LELIS, Isabel. A construção social da profissão docente no Brasil: uma rede de histórias. In: TARDIF, Maurice; LESSARD, Claude (Orgs.). O ofício de professor: história, perspectivas e desafios internacionais. Petrópolis: Vozes, 2008. p. 54-66.

LODI, Jurandir. [O Colégio Pedro II]. Rio de Janeiro: FGV/CPDOC, [1940]. (GC g 1935.10.18/1, r. 36).

MASSUNAGA, Magda Rigoud Pantoja. O Colégio Pedro Il e o ensino secundário brasileiro: 1930-1961. 1989. Dissertação (Mestrado em Educação) - Universidade Federal do Rio de Janeiro/UFRJ, Rio de Janeiro, 1989.

MONTEIRO, Clóvis de Rêgo. Relatório do Diretor do Colégio Pedro II - Internato ao Exmo. Sr. Ministro da Educação e Saúde. Relativo aos anos de 1938 a 1943. Rio de Janeiro: [s.n.], 1944.

NAGLE, Jorge. Educação e sociedade na Primeira República. São Paulo: Pedagógica e Universitária Ltda., 1974.

NUNES, Maria Thetis. Ensino secundário e sociedade brasileira. Textos brasileiros de Pedagogia. Estado da Guanabara: Instituto Superior de Estudos Brasileiros, 1962.

SILVA, Geraldo Bastos. A educação secundária: perspectiva histórica e teoria. São Paulo: Editora Nacional, 1969.

SOARES, Jefferson da Costa. Dos professores 'estranhos' aos catedráticos: aspectos da construção da identidade profissional docente no Colégio Pedro II (1925-1945). 2014. 
Tese (Doutorado em Educação) - Departamento de Educação, PUC-Rio, Rio de Janeiro, 2014.

JEFFERSON DA COSTA SOARES é professor assistente - doutor do Departamento de Educação da Pontifícia Universidade Católica do Rio de Janeiro (PUC-Rio). Bacharel e Licenciado em Ciências Sociais pela Universidade Federal do Rio de Janeiro - UFRJ (2005). Mestre em Educação pela Universidade Federal do Rio de Janeiro - UFRJ (2009). Doutor em Ciências Humanas - Educação pela Pontifícia Universidade Católica do Rio de Janeiro - PUCRio (2014). Membro da Sociedade Brasileira de História da Educação (SBHE). No Doutorado, foi bolsista do Programa Nota 10 da Fundação Carlos Chagas Filho de Amparo à Pesquisa do Estado do Rio de Janeiro (Faperj). Atuou no desenvolvimento de trabalho social em comunidades. Tem atuado principalmente nas áreas de Educação Brasileira, História da Educação, História do Currículo e das Disciplinas Escolares, História da Profissão Docente e Ensino de Sociologia. Realizou estágios de Pós-Doutorado como bolsista Capes (PNPD) na PUC-Rio entre abril de 2014 e novembro de 2016.

Endereço: Rua Marquês de São Vicente, 225, Gávea, Prédio Cardeal Leme, 10 andar, 22451-900, Rio de Janeiro/RJ, Brasil.

E-mail: jefics@puc-rio.br

GUSTAVO DA MOTTA SILVA é professor da Secretaria Municipal de Educação do Rio de Janeiro e da Secretaria Municipal de Educação de Duque de Caxias. Possui graduação de Licenciatura em Educação Física pela Universidade Federal do Rio de Janeiro (UFRJ), Mestrado em Educação pela Universidade Federal do Rio de Janeiro (UFRJ) e Doutorado em Ciências Humanas - Educação pela Pontifícia Universidade Católica do Rio de Janeiro (PUCRio). Participa como pesquisador registrado no CNPq do Núcleo de Estudos Sociocorporais e Pedagógicos em Educação Física e Esportes (Nespefe/UFRJ) e do grupo de pesquisa História da Profissão Docente (Prodoc/PUC-Rio). É membro associado da Associação Brasileira de Pesquisa (Auto)Biográfica (Biograph), da Sociedade Brasileira de História da Educação (SBHE) e do Colégio Brasileiro de Ciências do Esporte (CBCE), atuando principalmente nos seguintes temas: Formação de Professores, Corpo, História da Educação, História da Educação Física e Educação Física.

Endereço: Avenida Adolpho de Vasconcelos, 245 - ap. 1601, 22793-380, Rio de Janeiro/RJ, Brasil.

E-mail: gustavomotta1990@hotmail.com

Recebido em 09 de junho de 2017.

Aceito em 19 de agosto de 2017. 